\title{
Urinary isoamylases in the diagnosis of chronic pancreatitis
}

\author{
S. E. AW, J. R. HOBBS, AND I. D. P. WOOTTON \\ From the Department of Chemical Pathology, Royal Postgraduate Medical School, London
}

EDITORIAL COMMENT The proportion of pancreatic to salivary isoenzymes of alpha amylase has been measured in 24-hour samples of urine and the absolute value of the isoenzymes calculated from urinary amylase values. In seven of eight patients exocrine deficiency of the pancreas was accompanied by an altered ratio of pancreatic to salivary isoamylases.

The quantitation of isoenzymes in body fluids has obvious applications in the diagnosis of disease. $\alpha$-Amylase (E.C. 3.2.1.1.), of molecular weight 50,000 , also occurs in multiple molecular forms. This heterogeneity was initially discovered in animals and later extended to man. The evidence has been principally electrophoretic (Nørby, 1964; Muus and Vnenchak, 1964: Berk, Searcey, Hayashi, and Ujihira, 1965; Kamarýt and Laxová, 1965;Aw, 1966). Extracts of salivary glands and pancreas, saliva, serum, and urine were shown to contain cathodally running bands of amylolytic activity differing only slightly in mobility. Recently the isoenzymes of amylase (isoamylases) from human pancreas, saliva, and milk have been partially purified with the use of Deae Sephadex and gel filtration thus demonstrating a chromatographic heterogeneity as well (Aw and Hobbs, 1966).

Urinary isoamylases are separable into 'pancreatic' and 'salivary' according to their electrophoretic mobilities compared with marker pancreatic and salivary enzymes. This organ specificity may, in fact, be oversimplified (see Discussion). It is well known that patients with chronic pancreatitis more often than not have serum and urinary amylase values within normal limits. We were interested in studying urinary isoamylase patterns and in finding out whether patients with exocrine pancreatic deficiency exhibited a decrease in the activity of the pancreatic zone.

\section{MATERIALS}

Twenty-four-hour urine collections, preserved with toluene, were obtained from three groups of people.

GROUP 1 Twenty-nine patients with no history or other evidence of exocrine pancreatic disease: this group also included five normal individuals. Total was $\mathbf{3 4}$.
GROUP 2 Seven cases of chronic pancreatitis diagnosed on the basis of history, clinical findings, and one or more of the following - pancreatic pseudocyst or calcification on radiographs, abnormal glucose tolerance curves, subnormal pancreatic function tests, and findings at operation. A patient who had total pancreatectomy for carcinoma of the pancreas. Total was eight.

GROUP 3 Four patients with diarrhoea of small bowel origin, three with radiological appearance of Crohn's disease. Two of them had the diagnosis confirmed surgically. A patient with intestinal alactasia. A patient with gross steatorrhoea who also suffered from diabetes mellitus whose pancreatic function tests results were normal. Total was six.

None of the members of the groups had overt kidney or liver dysfunction.

METHOD

Aliquots of the urines were filtered, concentrated by ultrafiltration to about $1 / 20$ th their original volumes, and deep-frozen in small plastic thimbles till used.

Urinary amylase was estimated as described by Wootton (1964).

Electrophoresis was carried out in a Wieme type apparatus on agar-coated microscope slides made in

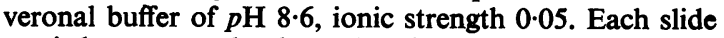
carried two sample slots placed $1 \mathrm{~cm}$. away from the midline towards the side of the anode. The slots were made by inserting the short side of a $6 \times 10 \mathrm{~mm}$. strip of filter paper (Whatman no. 3MM) into the agar and allowing the buffer to creep up by 4 to $5 \mathrm{~mm}$. before withdrawing the paper. Urine samples of about $2 \mu \mathrm{l}$. were applied in each slot. Cellulose acetate can be employed as the separating medium though a longer run of two hours is needed to produce a separation comparable to that of agar on the Wieme apparatus.

The electrophoretic run was made at 200 volts, 20 mA per slide, and stopped after exactly one hour. Cellulose acetate strips cut to size were laid on the agar to obtain an imprint of the zymogram pattern and 
transferred to starch substrate plate (Aw, 1966) for an hour's incubation at $37^{\circ} \mathrm{C}$. The strips were then lifted off carefully and the starch plate was stained in a bath consisting of $50 \mathrm{ml}$. working iodine solution used in the amylase estimation and $60 \mathrm{ml}$. of absolute alcohol. When the undigested background was uniformly purple and the digested bands stood out clearly on viewing against a diffuse light source the wash was terminated. After drying a few minutes in air the plates were scanned. We used a Joyce Loebl double-beam automatic recording microdensitometer with an aperture setting of $1 \mathrm{~mm}$. and a magnification of 5 (Model Mark 111B). If the Joyce Loebel Chromoscan, a double-beam recording and integrating densitometer, is used the grey-wedge (optical attennuator) is reversed from the normal position, that is, the dense end is now on the right instead of the left. This enables the optically clear areas of the isoenzyme bands to be scanned by transmission and recorded in the usual way.

The sample holder of the Chromoscan can accommodate starch plates of $2.5 \mathrm{~cm}$. width, that of a microscope slide. But starch gel casts on microscope slides are difficult to handle being easily torn or shed during the wash. This difficulty is avoided by the following procedure which has been used for preparing agar slides. Molten agar is allowed to solidify in Petri dishes. Four microscope slides are placed on the hydrostatically level base so formed. Into the dish is poured the hot degassed starch solution (about $33 \mathrm{ml}$.) calculated to give a starch gel thickness of about $1 \mathrm{~mm}$. over the slides. Cellulose acetate transfers are carefully positioned over the slides, the whole incubated, and staining carried out with the slides in situ. Individual slides are cut out with a scalpel, air-dried, and scanned.

\section{RESULTS}

The isoamylases of the urinary zymograms are numbered from the slowest, nearest the cathode, to the fastest in the order P1, P2, P3 (pancreatic group) and S1, S2, S3 (salivary group). Three basic patterns are seen according to the location and number of the pancreatic bands. The salivary patterns usually contain $\mathbf{S 1}$ or $\mathbf{S 1}$ and $\mathbf{S 2}$. Three representative scans are shown in Figure 1. Of the total 40 control urines examined, 35 were type 1 , three were type 2 , and two were type 3 . The proportions of pancreatic and salivary isoamylases were measured from the scans and the absolute values of the isoenzymes calculated from the urinary amylase values. The ratios of pancreatic to salivary enzymes of the three groups were then calculated. The results are set out in Table I.

Inspection alone often suffices to reveal whether a zymogram is deficient or not in pancreatic amylase (Fig. 2). This is especially so with type 1 urines which form the majority. Urine 10 (Table I) presented an equivocal zymogram on inspection which on scanning gave a ratio of 0.9 . The urines of patients

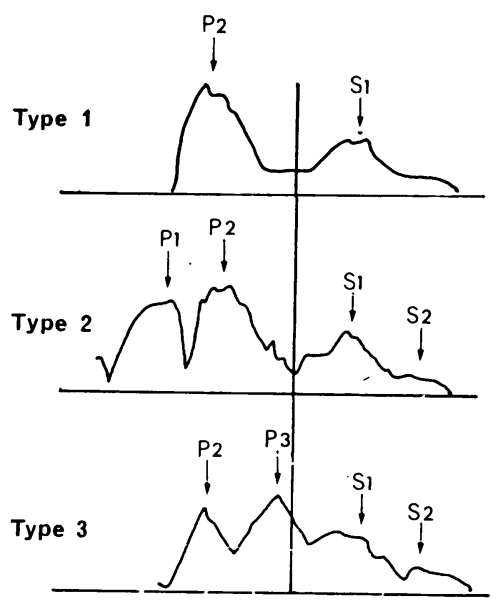

FIG. 1. Scans of three representative normal zymograms of urinary isoamylases. Vertical line marks off pancreatic $(P)$ from salivary $(S)$ isoamylases, which are numbered from the slowest isoenzyme. About $90 \%$ of normal urines are type 1 in their isoamylase pattern.

\section{TABLE I}

TABULATED RESULTS OF SURVEY OF URINARY AMYLASE ON 24-HOUR URINE COLLECTIONS IN GROUP 1

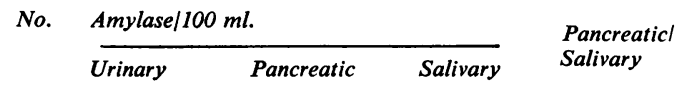

\begin{tabular}{|c|c|c|c|c|}
\hline 1 & 200 & 155 & 45 & 3.4 \\
\hline 2 & 121 & 76 & 45 & $1 \cdot 7$ \\
\hline 3 & 140 & 77 & 63 & $1 \cdot 2$ \\
\hline 4 & 218 & 138 & 80 & $1 \cdot 7$ \\
\hline 5 & 150 & 95 & 55 & $1 \cdot 7$ \\
\hline 6 & 275 & 187 & 88 & $2 \cdot 1$ \\
\hline 7 & 103 & 78 & 25 & $3 \cdot 1$ \\
\hline 8 & 110 & 67 & 43 & 1.5 \\
\hline 9 & 133 & 81 & 52 & 1.6 \\
\hline 10 & 325 & 157 & 168 & 0.9 \\
\hline 11 & 85 & 62 & 23 & $2 \cdot 7$ \\
\hline 12 & 143 & 89 & 54 & 1.6 \\
\hline 13 & 122 & 81 & 41 & $2 \cdot 0$ \\
\hline 14 & 170 & 110 & 60 & 1.8 \\
\hline 15 & 400 & 250 & 150 & $1 \cdot 7$ \\
\hline 16 & 145 & 82 & 63 & $1 \cdot 3$ \\
\hline 17 & 200 & 116 & 84 & 1.4 \\
\hline 18 & 147 & 91 & 56 & 1.7 \\
\hline 19 & 109 & 71 & 38 & 1.9 \\
\hline 20 & 282 & 216 & 66 & $3 \cdot 3$ \\
\hline 21 & 61 & 41 & 20 & $2 \cdot 0$ \\
\hline 22 & 50 & 35 & 15 & $2 \cdot 3$ \\
\hline 23 & 180 & 106 & 74 & $1 \cdot 4$ \\
\hline 24 & 222 & 163 & 59 & $2 \cdot 8$ \\
\hline 25 & 85 & 47 & 38 & $1 \cdot 2$ \\
\hline 26 & 262 & 159 & 103 & $1 \cdot 5$ \\
\hline 27 & 266 & 144 & 122 & 12 \\
\hline 28 & 88 & 48 & 40 & 12 \\
\hline 29 & 78 & 51 & 27 & 1.9 \\
\hline 30 & 206 & 134 & 72 & 1.9 \\
\hline 31 & 170 & 116 & 54 & $2 \cdot 1$ \\
\hline 32 & 200 & 125 & 75 & $1 \cdot 7$ \\
\hline 33 & 103 & 64 & 39 & 1.6 \\
\hline 34 & 113 & 73 & 40 & $1 \cdot 8$ \\
\hline $\begin{array}{l}\text { Mean } \\
\text { S.D. } \\
\text { Range }\end{array}$ & $\begin{array}{c}165 \\
77 \\
50-400\end{array}$ & $\begin{array}{c}105 \\
48 \\
35-250\end{array}$ & $\begin{array}{c}61 \\
53 \\
15-168\end{array}$ & $0.9-3.4$ \\
\hline
\end{tabular}


TABLE II

FINDINGS FROM EIGHT PATIENTS WITH KNOWN PANCREATIC DISEASE (GROUP 2) AND CASES OF GROUP 3

No. Patient Nature of Urinary Pancreatic Salivary Pancreaticl Disease Amylase Isoamylase Amylase Salivary

\begin{tabular}{|c|c|c|c|c|c|c|}
\hline \multicolumn{7}{|c|}{ Group 2 } \\
\hline 1 & J. M. & $\begin{array}{l}\text { Carcinoma } \\
\text { of pancreas } \\
\text { (pancrea- } \\
\text { tectomy) }\end{array}$ & 111 & 31 & 80 & 0.4 \\
\hline 2 & E.H. & $\begin{array}{l}\text { Chronic } \\
\text { pancreatitis }\end{array}$ & 88 & 15 & 73 & 0.2 \\
\hline 3 & J.I. & $\begin{array}{l}\text { Chronic } \\
\text { pancreatitis }\end{array}$ & 290 & 101 & 189 & 0.5 \\
\hline 4 & C.P. & $\begin{array}{l}\text { Chronic } \\
\text { pancreatitis }\end{array}$ & 90 & 21 & 69 & $0 \cdot 3$ \\
\hline 5 & M.M. & $\begin{array}{l}\text { Chronic } \\
\text { pancreatitis }\end{array}$ & 222 & 86 & 136 & 0.6 \\
\hline 6 & E.M. & $\begin{array}{l}\text { Chronic } \\
\text { pancreatitis }\end{array}$ & 60 & 0 & 60 & 0 \\
\hline 7 & L.W. & $\begin{array}{l}\text { Chronic } \\
\text { pancreatitis }\end{array}$ & 121 & 81 & 40 & $2 \cdot 0$ \\
\hline 8 & W.R. & $\begin{array}{l}\text { Chronic } \\
\text { pancreatitis }\end{array}$ & 88 & 27 & 59 & 0.5 \\
\hline \multicolumn{7}{|l|}{ Group 3} \\
\hline 1 & G.S. & Alactasia & 282 & 173 & 109 & 1.6 \\
\hline 2 & E.L. & $\begin{array}{l}\text { Crohn's } \\
\text { disease }\end{array}$ & 120 & 73 & 47 & 1.5 \\
\hline 3 & M.B. & $\begin{array}{l}\text { Crohn's } \\
\text { disease }\end{array}$ & 155 & 109 & 46 & $2 \cdot 3$ \\
\hline 4 & N.B. & $\begin{array}{l}\text { Crohn's } \\
\text { disease }\end{array}$ & 127 & 77 & 50 & 1.5 \\
\hline 5 & C.B. & $\begin{array}{l}\text { Idiopathic } \\
\text { steatorrhoea }\end{array}$ & $\begin{array}{l}160 \\
160\end{array}$ & $\begin{array}{l}98 \\
98\end{array}$ & $\begin{array}{l}62 \\
62\end{array}$ & $\begin{array}{l}1.6 \\
1.6\end{array}$ \\
\hline 6 & H.S. & $\begin{array}{l}\text { Idiopathic } \\
\text { steatorrhoea }\end{array}$ & 155 & 96 & 59 & 1.6 \\
\hline
\end{tabular}

from groups 1 and 3 show a preponderance of pancreatic over the salivary enzyme which was confirmed by the scans subsequently. From group 2, however, seven of eight zymograms revealed a decrease of pancreatic amylase activity in relation to the salivary. We were not able to obtain another urine specimen from patient $\mathbf{L}$. W. for a repeat experiment. Figure 3 shows five scans from group 2 patients. Figure $4 \mathrm{~A}$ and $\mathrm{B}$ illustrate two types of urines which could be mistaken for one of the urines from group 2 shown in the same Figure 3. Figure $4 \mathrm{~A}$ is a scan of the urinary isoamylase pattern

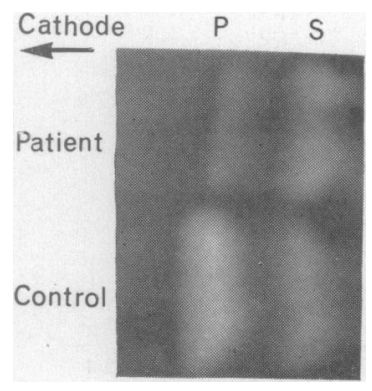

FIG. 2. Urinary zymograms of a normal individual and that of $a$ patient (C.P.) showing decrease of pancreatic amylase $(P)$ in the latter in comparison with salivary amylase $(S)$.

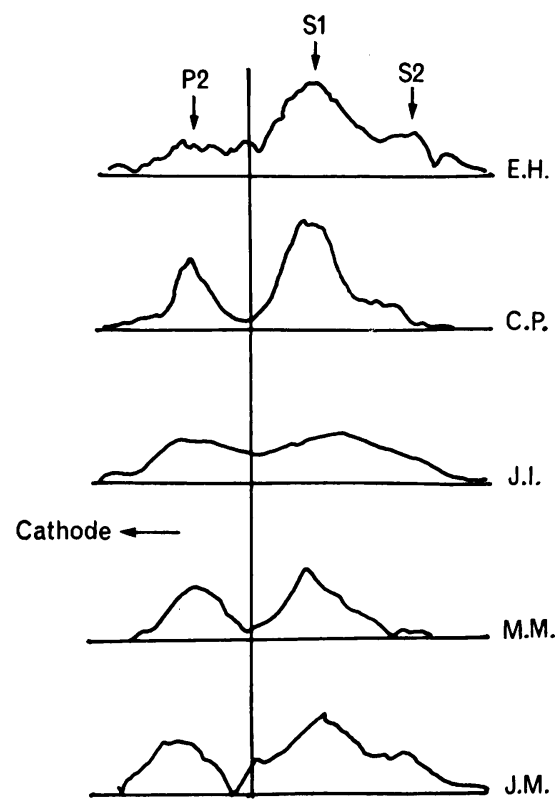

FIG. 3. Scans of urinary zymograms from five patients with deficient exocrine pancreatic function.

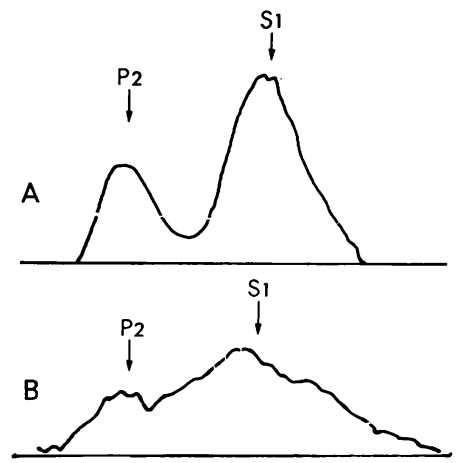

FIG. 4. Scans of urinary zymograms from $(A)$ 6-month old infant and (B) 4-year-old boy with mumps.

from a 6-month-old infant. Pancreatic function is not well-established in the first year of life (Janowitz and Dreiling, 1959). Figure 4B is a scan for 4-year-old boy with mumps. In both these urines, for different reasons, the pancreatic isoamy. lase appears to be relatively less than the salivary.

In group 1 the correlation coefficients between pancreatic and total amylase is 0.96 , that between salivary and total amylase is 0.91 . Distribution histograms show an increase in skewness in the order salivary, pancreatic, and total amylase. A plot of pancreatic against salivary amylase values 


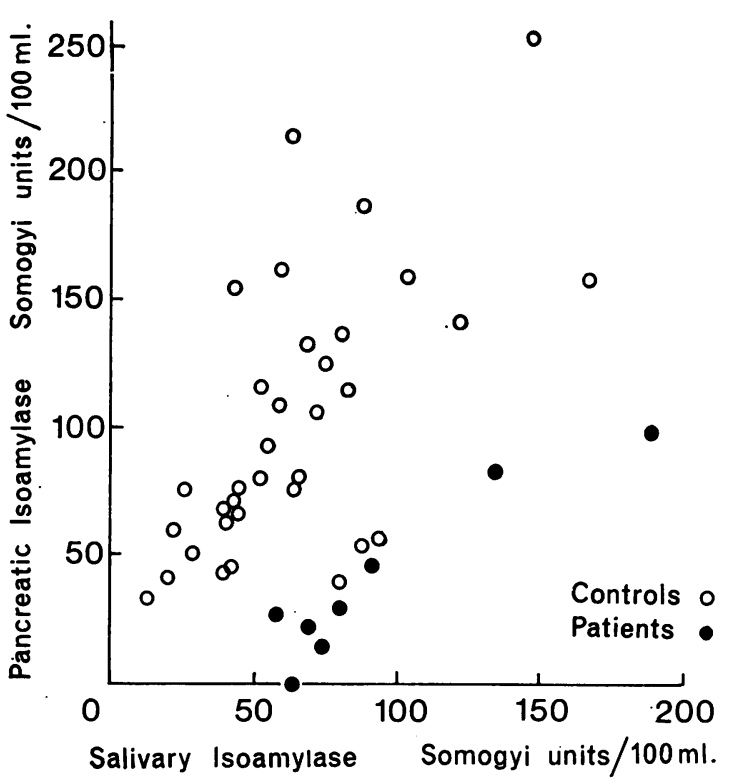

FIG. 5. Plot of pancreatic against salivary isoamylase values in urines of group $1(\bigcirc)$ and group $2(\bigcirc)$.

also demonstrates a scatter arising from greater variation in pancreatic values than salivary (Fig. 5).

\section{DISCUSSION}

The values of urinary amylases obtained are as expected for an enzyme in which variations between individuals are large but those exhibited by single individuals are small (Somogyi, 1941; Budd, Walter, Harris, and Knight, 1959). The mean enzyme concentration per $100 \mathrm{ml}$. urine was 165 Somogyi units with a S.D. of 77. On the basis of a two-hour collection from 100 normal people Gambrill and Mason (1964) found the mean value of urinary excretion per hour to be 127 Roe units with a S.D. of 64 (Smith and Roe units $\times 1 \cdot 1=$ Somogyi unit).

With such a wide range of values for the total amylase, diagnosing pancreatic deficiency is rarely possible. In fact all five cases of advanced chronic pancreatitis with steatorrhoea investigated by Kirshen, Gambrill, and Mason (1965) had normal serum and urinary amylase levels. In our series if only the total urinary amylase were considered it would not be pcssible to diagnose any of the eight cases; if the pancreatic fraction alone were considered it would implicate five patients (J. M., E. H., C. P., E. M., and W. R.). When the ratio of the amounts of pancreatic to salivary amylase is the criterion it is possible to diagnose a deficiency in seven of the eight cases.
In man there are at least five established sources of $\alpha$-amylase, namely, the salivary glands, pancreas, the intestinal epithelium (Thomson, 1965), the Fallopian tube and 'tubelike' epithelium of Mullerian and mesonephric origin (Green, 1957), and the lactating mammary gland (Kuttner and Somogyi, 1934). There is evidence that the liver may regulate the serum level of the enzyme (Gray, Probstein, and Heifetz 1941) but this has not been confirmed (Cummins and Bockus, 1951). Franzini and Moda (1965) have reported an alteration of urinary isoamylase pattern with paper electrophoresis in acute hepatitis. Whether this is expressive of a derangement in a control mechanism normally exercised by the liver or an efflux of abnormal amounts of a liver enzyme remains to be determined. A search for the liver enzyme has produced negative results, at least in post-mortem tissues (Somogyi, 1941; Aw and Hobbs, 1966). More recently Joseph, Olivero, and Ressler (1966) detected an 'amylase' band whose electrophoretic mobility in $0.4 \%$ agar at $p \mathbf{H} 7.25$ was even slower than pancreatic amylase. The enzyme was found in human liver extracts and serum. It was stainable with o-dianisidine in a ternary enzyme system consisting of maltase, glucose oxidase. and peroxidase. Unlike pancreatic and salivary amylase it failed to prevent iodine-starch colour reaction. These findings are interesting in relation to a report by Rosenfeld (1964) of the isolation of $\gamma$-amylase from human liver and kidneys. This enzyme is an exopolyglucosidase which splits glycogen and starch with the formation of high molecular weight dextrins and glucose. Thomson (1965) isolated small amounts of a similar enzyme from human small intestine mucosa besides the more abundant $\alpha$-amylase. Our electrophoresis experiments with jejunal mucosal extracts yielded the P2 isoenzyme. In several ovarian cyst fluids examined amylolytic activity with slightly greater mobility than S1 was found (unpublished observations). Milk contains mainly salivary type enzyme with a small amount of activity in the P2 region (Aw and Hobbs, 1966).

It is probable, therefore, that in normal circumstances the pancreas, salivary glands, and the gut constitute the main sources of serum $\alpha$-amylase activity. The behaviour of the urinary pancreatic complex in acute pancreatitis and the chromatographic isolation of P1 and P2 from extracts (of pancreas) offer strong corroborative evidence that the urinary isoenzymes $\mathbf{P 1}$ and P2 are largely pancreatic in origin.

Of 120 children examined, serum amylases corresponding to P2 and S1 were found in $109(90.9 \%)$ (Kamarýt and Laxová, 1965). The proportion in our smaller series is $87.5 \%$. In the remaining 11 
children, the pancreatic fraction was doubled. The same authors obtained the interesting results with a group of 14 diabetic children aged from 10 to 15 years where in 10 a considerable increase of activity of the salivary fraction was noted. We investigated three diabetic patients not in the series. Two of them had the disease as adults and their amylase ratios were within normal limits. The third, who had suffered from the disease since the age of 5 , had the ratio 0.8. Advanced dysfunction of the islet or acinar tissue has adverse effects on each other and the association of frank diabetes with chronic pancreatitis is well documented.

Wieriks (1964) demonstrated that the buccal application of bacterial $\alpha$-amylase to rabbits can result in the production of precipitating antibodies in the sera. Furthermore it has also been observed that patients with chronic pancreatitis occasionally develop an avidity in the intestinal absorption of various substances (Dawson, 1964). If in fact the intestinal epithelium becomes abnormally permeable to large molecules the ingestion of pancreatic supplements may interfere with the urinary amylase pattern. Two commercial preparations we tested contain amylases in the region of the normal isoamylases. Crystalline hog pancreatic amylase gives a zymogram pattern very similar to that of a type 1 urine. As a precaution patients should abstain from taking supplements for a few days before the collection of the urine. The test will only be of value where the total urinary amylase is within the normal limits.

Amylase is cleared from the blood by simple filtration and is not reabsorbed in the tubules (McGeachin and Hargan, 1956). Impaired renal clearance has been found to cause elevated amylase values in the serum and lowered values in the urine e.g., Budd et al., 1959). This is an uncommon finding (Gross, Parkin, Maher, and Power, 1960). However, it is highly unlikely that the filtration of two species of molecules so similar as pancreatic and salivary amylase could be separately affected. The ratio of the two is likely to remain the same as that of the parent plasma even when poor renal function lowers the amount of urinary enzyme.

\section{SUMMARY}

A simple method is described for the electrophoretic separation of urinary pancreatic and salivary isoenzymes of $\alpha$-amylase and this offers a convenient screening test. The ratio of the amounts of pancreatic to salivary isoamylases in the urine is proposed as an index of deficient exocrine pancreatic function. Visual assessment of the urinary zymogram is frequently sufficient for a diagnosis. Studies were made on 40 controls and eight patients with known pancreatic deficiency. Seven of the eight patients had abnormal zymograms and low ratios. The results and possible factors influencing the zymogram pattern are discussed.

We are grateful to those of the hospital staff who supplied us with the urine collections. For providing the patients in group 2 of our study, we would like to thank Dr. G. Neale of the Gastroenterology Unit in Hammersmith Hospital, Dr. H. Bramwell Cook of Central Middlesex Hospital, Mr A. M. Desmond of St. James's Hospital. We also want to thank Dr. F. H. Doyle for his ready kindness in allowing us the use of the microdensitometer in the Department of Radiodiagnosis.

One of us (S. E.) is on an overseas training scholarship from the University of Singapore.

\section{REFERENCES}

Aw, S. E. (1966). Separation of urinary isoamylases on cellulose acetate. Nature (Lond.), 209, 298-300.

- , and Hobbs, J. R. (1966). Human isoamylases. Biochem. J., 99, $16 \mathrm{P}$.

Berk, J. E., Searcy, R. L., Hayashi, S., and Ujihira, I. (1965). Distribution of serum amylase in man and animals, J. Amer. med. Ass., 192, 389-393.

Budd, J. J., Jr., Walter, K. E., Harris, M. L., and Knight, W. A., Jr., (1959). Urine diastase in the evaluation of pancreatic disease. Gastroenterology, 36, 333-353.

Cummins, A. J.,and Bockus, H. L. (1951). Abnormal serum pancreatic enzyme values in liver disease. Ibid, 18, 518-529.

Dawson, A. M. (1964). Disturbances of intestinal absorption. In Recent Advances in Medicine, edited by D. N. Baron, N. Compston, and A. M. Dawson, pp. 282-297. Churchill, London.

Franzini, C., and Moda, S. (1965). Human urinary amylolytic enzymes in acute hepatitis. J. clin. Path., 18, 775-776.

Gambill, E. E., and Mason, H. L. (1964). Urinary amylase excretion per hour in 100 individuals without gastrointestinal disease or renal insufficiency, J. Lab. clin. Med., 63, 173-176.

Gray, S. H., Probstein, J. G., and Heifetz, C. J. (1941). Clinical studies on blood diastase. Arch. intern. Med., 67, 805-818.

Green, C. L. (1957). Identification of alpha-amylase as a secretion of the human fallopian tube and 'tube-like' epithelium of Müllerian and mesonephric duct origin. Amer. J. Obstet. Gynec., 73, 402-408.

Gross, J. B., Parkin, T. W., Maher, F. T., and Power, M. H. (1960) Serum amylase and lipase values in renal and extrarenal azotemia. Gastroenterology, 39, 76-82.

Janowitz, H. D., and Dreiling, D. A. (1959). The plasma amylase. Source, regulation and diagnostic significance. Amer. J. Med. 27, 924-935.

Joseph. R. R., Olivero, E., and Ressler, N. (1966). Electrophoretic study of human isoamylases. Gastroenterology, 51, 377-382.

Kamarýt, J., and Laxová, R. (1965). Amylase heterogeneity. Some genetic and clinical aspects. Humangenetik, 1, 579-586.

Kirshen, R., Gambill, E. E., and Mason, H. L. (1965). Comparison of urinary and serum amylase values following pancreatic stimulation in patients with and without pancreatic disease. Gastroenterology, 48, 579-583.

Kuttner, M., and Somogyi, M. (1934). Diastase in milk. Proc. Soc. exp. Biol. (N.Y.), 32, 564-566.

McGeachin, R. L., and Hargan, L. A. (1956). Renal clearance of amylase in man. J. appl. Physiol., 9, 129-131.

Muus, J., and Vnenchak, J. M. (1964). Isozymes of salivary amylase. Nature (Lond.), 204, 283-285.

Nørby, S. (1964). Electrophoretic non-identity of human salivary and pancreatic amylases. Exp. Cell Res.,36, 663-666. 
Rosenfeld, E. L. (1964). Animal tissue $\gamma$-amylase and its role in the metabolism of glycogen. In Control of Glycogen Metabolism: Ciba Foundation Symposium, edited by W. J. Whelan and M. P. Cameron, pp. 176-189. Churchill, London.

Somogyi, M. (1941). Diastatic activity of human blood. Arch. intern. Med., 67, 665-679.
Thomson, D. L. (1965). Separation and characterisation of human intestinal-mucosal amylases. Canad. med. Ass. J., 92, 370-371.

Wieriks, J. (1964). Resorption of $\alpha$-amylase upon buccal application. Arch. int. Pharmacodyn., 151, 126-135.

Wootton, I. D. P. (1964). Micro-analysis in Medical Biochemistry, 4th ed., p. 106. Churchill, London.

\section{The June 1967 Issue}

\section{THE JUNE 1967 ISSUE CONTAINS THE FOLLOWING PAPERS}

Mesenteric arterial disease: the present position ADRIAN MARSTON

An arteriographic study of mesenteric arterial disease A. P. DICK, R. GRAFF, D. MCC. GREGG, N. PETERS, and M. SARNER

I Large vessel changes

Physical and psychological evaluation of 'non-organic' abdominal pain OSCAR W. HILL AND LAURENCE BLENDIS

An analysis of the autonomic control of gastrointestinal motility in the cat JULIAN NEELY and B. N. CATCHPOLE

Comparison of the effects of a gastrin extract and a synthetic pentapeptide on gastrointestinal motility in the cat JULIAN NEELY

Effect of $E$. coli antigens, tuberculin, and phytohaemagglutinin upon ulcerative colitis lymphocytes S. STEFANI and S. FINK

Peptic ulceration and gastrointestinal bleeding in pancreatitis I. N. MARKS, S. BANK, J. H. LOUW, and JACK FARMAN

Pancreatic function and the absorption of fat, iron, vitamin $\mathbf{B}_{12}$, and calcium after total gastrectomy for gastric cancer K. FISCHERMANN, S. HARLY, H. WORNING, and A. ZACHO
Difference in responses between dogs and cats to large doses of gastrin on gastric secretion SVERRE EMÅs and MORTON I. GROSSMAN

Effect of 1-hyoscyamine on gastric secretion of acid and intrinsic factor in man G. DOTEVALL, A. WALAN, and A. WEINFELD

Clinical course, late results, and pathological nature of inflammatory disease of the colon initially sparing the rectum BURTON I. KORELITZ

Splenomegaly and renal displacement COLIN E. MACKINTOSH and LOUIS KREEL

Action of various new analgesic drugs on the human common bile duct D. S. HOPTON and H. B. TORRANCE

Relationship between aspirin taking and gastroduodenal haemorrhage D. J. PARRY and PHILIP H. N. WOOD

Myenteric plexus in Hirschsprung's disease BARBARA SMITH

Congenital duodenal stenosis in a patient aged 78 years P. DORKEN and W. S. EVANS

Copies are still available and may be obtained from the PUBLISHING MANAGER, BRITISH MEDICAL ASSOCIATION, TAVISTOCK SQUARE, W.C.1, price 18s. 6D. 